\title{
Measuring Disinflation Credibility in Emerging Markets: A Bayesian Approach with an Application to Turkey
}

Marco Rossi and Alessandro Rebucci 


\title{
IMF Working Paper
}

European Department and Research Department

\section{Measuring Disinflation Credibility in Emerging Markets: A Bayesian Approach with an Application to Turkey}

\author{
Prepared by Marco Rossi and Alessandro Rebucci ${ }^{1}$
}

Authorized for distribution by Reza Moghadam and Gian Maria Milesi-Ferretti

November 2004

\begin{abstract}
This Working Paper should not be reported as representing the views of the IMF. The views expressed in this Working Paper are those of the author(s) and do not necessarily represent those of the IMF or IMF policy. Working Papers describe research in progress by the author(s) and are published to elicit comments and to further debate.
\end{abstract}

This paper presents an empirical measure of disinflation credibility and discusses its evolution in Turkey since the 2001 crisis. The results indicate that credibility has improved markedly over this period, boding well for the future of disinflation in Turkey.

JEL Classification Numbers: C11, E58, F37

Keywords: Bayesian Learning, Credibility, Disinflation, Mixing Estimation, Turkey

Author(s) E-Mail Address: mrossi@imf.org and arebucci@imf.org

\footnotetext{
${ }^{1}$ The authors are grateful to Oya Celasun, Hakan Kara, Gian Maria Milesi-Ferretti, Reza Moghadam, Alessandro Prati, and Eray Yucel for useful comments and discussions. The usual disclaimer applies.
} 


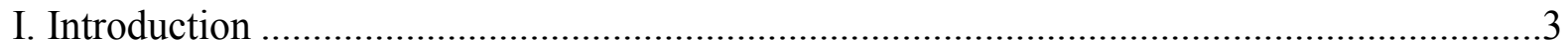

II. Measuring Disinflation Credibility .........................................................................4

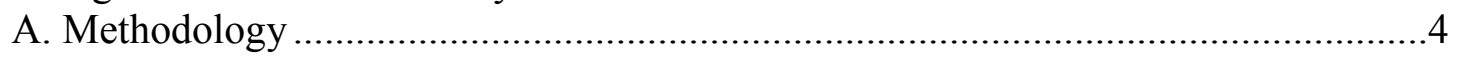

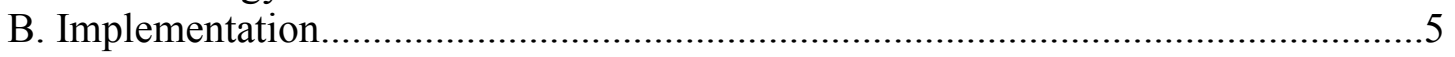

III. Disinflation Credibility in Turkey …..................................................................... 7

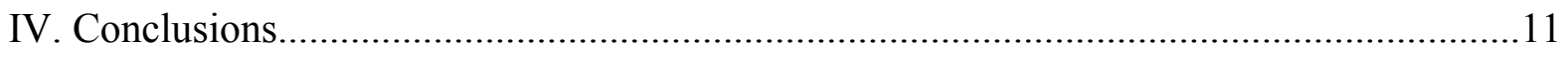

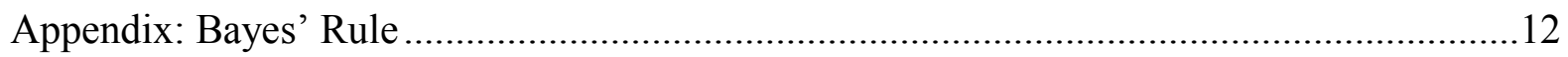

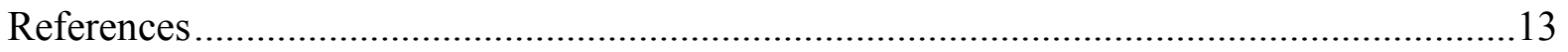

Tables

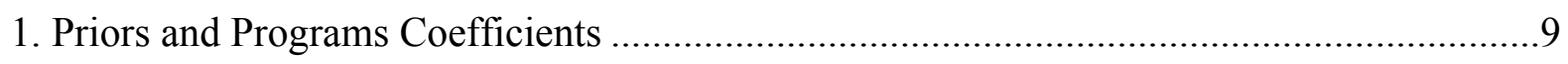

Figures

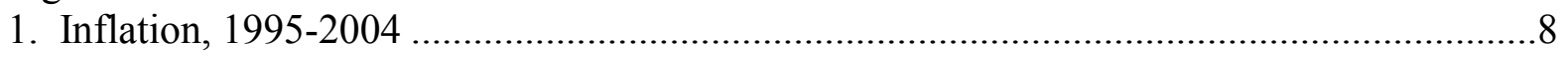

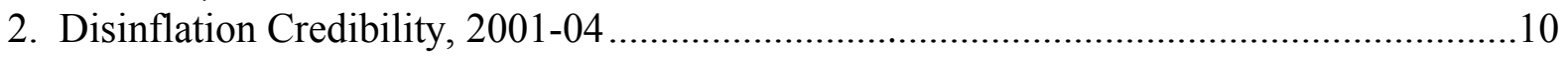




\section{INTRODUCTION}

Credibility is key to the success of a disinflationary program. By reducing inflationary expectations, with its attendant impact on wage and price setting behavior, a fully credible policy, in principle, can deliver a sharp drop in inflation with limited output losses. However in practice, credibility can only improve gradually. When switching from a regime of high and persistent inflation to one of price stability, central banks typically try to strike a balance between the ambitious and the feasible. More specifically, central banks aim at reducing inflation over time as quickly as the public can learn about the policymaker's true intentions (King, 1996).

\section{Policymakers' ability to steer market confidence about the implementation of a} stabilization program rests on many factors. Time-inconsistency - that is, the fact that the ex post policies may differ from the ex ante optimal policies - is one reason why the public requires time to learn about the policymaker's true intentions. Credibility can also be weakened by the perception that the government's policies are not mutually consistent as in the case in which disinflation is pursued without measures to limit budget deficits.

Credibility, moreover, can be affected by factors that are beyond immediate government control or that the government can influence only in the medium term. In this regard, even a program that is both time and internally consistent may not be credible if policymakers lack the instruments either to implement it or to cope with exogenous shocks.

Since the 2001 crisis, Turkey has been implementing a far-reaching stabilization and reform program. Cognizant of the impact that the overall policy framework may have on the success of a disinflationary program, policymakers in Turkey have complemented their disinflation efforts with fiscal discipline and ambitious structural reforms. This approach has delivered the lowest inflation rate in decades. Policy credibility, however, will remain key to further disinflation, particularly at a level of inflation at which the trade-off between the speed of disinflation and output costs may become steeper.

This paper presents an empirical measure of disinflation credibility and discusses its evolution in Turkey since the 2001 crisis. While credibility is crucial to the success of any stabilization program, it is hard to measure because it is unobservable. In this paper, we measure credibility using an econometric approach that mimics the way economic agents learn about policymakers' true intentions and abilities. This measure does not require the existence of liquid government bond markets or a competitive financial industry, which are necessary instead when credibility is measured by extracting information from asset prices or by surveys of inflation expectations. The measure we propose is thus suitable to assess credibility in emerging market economies. The results indicate clearly that the credibility of the disinflation program launched by Turkey in the aftermath of the 2001 crisis has improved dramatically.

The rest of the paper is organized as follows. Section II motivates and describes the methodology we use to quantify disinflation credibility in general terms. It also illustrates the specific steps we follow in its practical application to the Turkish disinflation process. Section III applies this methodology to Turkey's stabilization program over the period since the 2001 financial crisis. Section IV concludes. 


\section{Measuring Disinflation Credibility}

Credibility is not hard to define. Credibility can be thought of as the public's degree of uncertainty regarding publicly announced policy objectives. Optimizing agents use all available information on current and past policies, as well as economic outcomes, to infer the policymaker's 'true' objectives. Policy credibility improves as agents become more and more convinced that policy outturns are indeed in line with the preannounced policy objectives. The credibility of any policy can therefore be interpreted as the probability, as assessed by agents, that policy outturns coincide with the policy targets.

But credibility is hard to measure. Credibility is unobservable as it relates to agents' perceptions of policymakers' actions and intentions. Several approaches have been used to measure credibility in the literature. ${ }^{2}$ These procedures range from the use of proxies for credible monetary frameworks — such as exchange rate variability (Christensen, 1987), central bank independence (Grilli et al., 1991), or inflation persistence (Alogoskoufis, 1992) - to the estimation of time-varying parameter methods (Mankiw et al., 1987), or the use of forecast-errors techniques (Blanchard, 1984 and Kremers, 1990), asset prices (Agénor and Taylor, 1993 and Revenga, 1993, respectively), and surveys of inflation expectations (Celasun, Gelos, and Prati, 2004).

In practice, central banks use various sources of information, including asset prices and expectation surveys, to assess the credibility of their own policy stance. Credibility measures derived from asset prices and surveys of financial market participants, however, have limitations, especially in emerging markets. In these economies, domestic bond markets may not be deep and liquid enough and financial market participants may not have sufficient incentives to reveal their true expectations to provide with reliable measures of credibility. These measures may also not represent inflation expectations of actual price setters in the broader economy (e. g., workers and firms).

\section{A. Methodology}

The measure of credibility proposed in this paper is an econometric estimate of the probability that inflation outturns are consistent with the announced monetary policy objectives. More specifically, following Baxter (1985) and Weber (1991), this measure is the probability that the estimated parameters of an econometric model of the inflation process are consistent with those implicit in the authorities' announced monetary policy objectives. As such, our measure captures how credibility improves while a specific policy is being implemented rather than when it is announced.

This credibility measure has three main advantages. First, it uses the aggregate consumer price index, which is available and relatively reliable in most emerging market economies. Second, it embeds information on actual price and wage setting behavior more fully than

\footnotetext{
${ }^{2}$ See Agénor and Taylor (1992) for a more detailed overview of the various procedures commonly used to measure credibility briefly summarized here.
} 
estimates of this behavior by financial market participants. Third, it captures the extent to which agents' expectations are backward- or forward-looking since it reflects the expectations embedded in the consumer price index. The measure, however, assumes the existence of a representative agent as far as price and wage setting behavior is concerned.

Like Baxter (1985), we assume that the representative agent "learns" in a Bayesian manner about the true policy and quantifies her belief econometrically. Bayesian learning is an intuitive way of thinking about agents' perceptions and is simple to implement econometrically. Agents know the functional form of the econometric model of the inflation process, but have only beliefs (i.e., prior probability distributions) on the true parameters of this model. They update these beliefs on the basis of new realizations of the inflation process, through Bayes' rule, to form posterior probability distributions of the true model parameters. ${ }^{3}$ By integrating these posterior density functions over the relevant parameter values, we can calculate the probability that the true parameters of the inflation process are consistent with those implicit in the publicly announced policy after each realization of the inflation process.

Unlike Baxter (1985), we focus on the final objective, inflation, rather than the instrument or the intermediate target of monetary policy. Baxter (1985) focuses on a policy rule whose consistency with the policy objectives, as perceived by the public, needs to be assessed. Reflecting the different policy framework under inflation targeting, we concentrate on inflation instead. We assume a certain data-generating process for inflation, and measure policy credibility by assessing the consistency of the actual inflation path with the targeted one under the government's monetary program. Disinflation, in particular in the Turkish context, crucially depends on the internal consistency and the feasibility of the overall stabilization program. ${ }^{4}$ By focusing on inflation, rather than on a specific monetary rule, our measure captures the credibility of the announced stabilization program as a whole, rather than of monetary policy per se.

\section{B. Implementation}

To implement the methodology described above, we need three ingredients. First, we need an econometric model of the disinflation process; second, a mapping from the authorities' policy objectives to the parameter values of this model; and, third, an estimation procedure to implement Bayesian learning econometrically.

The econometric model of the disinflation process that we posit is a simple autoregressive process of the first order, $\operatorname{AR}(1)$ :

$$
\Delta \pi_{\mathrm{t}}=\alpha+\beta \Delta \pi_{\mathrm{t}-1}+\mathrm{e}_{\mathrm{t}}
$$

\footnotetext{
${ }^{3}$ See the Appendix for Bayes' rule.

${ }^{4}$ See Celasun, Gelos, and Prati (2004) for an empirical analysis of the role of fiscal factors in determining inflation expectations in several emerging market economies, including Turkey.
} 
where the error term, $\mathrm{e}_{\mathrm{t}}$, is normally distributed with zero mean and variance $\sigma^{2}$. We assume that monthly changes in inflation follow an AR (1) primarily for simplicity. However, as simple as it is, this model can characterize the average speed of the disinflation process (i.e., the average change in the inflation rate $\alpha$ ), the persistence of temporary accelerations or decelerations in this process (i.e., deviations from the average change in the inflation rate $\beta$ ), and the volatility of the shocks producing these deviations (i.e., the variance of the innovations $\left.\sigma^{2}\right)^{5}$

The mapping from the authorities' policy objectives to the parameter values of the disinflation process above relies on the inflation target under IMF-supported programs. For each program, we can take the authorities' publicly announced annual inflation target and construct a projected monthly inflation path (see next section on how we derive these projections in the specific case of Turkey). We can then estimate equation (1) on monthly time series that include actual data (from the beginning of the sample period up to the announcement of the IMF-supported program considered) and the derived monthly projected path (from the program approval to the end of the projection period). This regression provides a set of coefficients for equation (1) consistent with the authorities' announced disinflation objectives in the absence of shocks, which we call "program" coefficients. In practice, shocks will cause the actual inflation path after the beginning of the IMF-supported program to deviate from the projected path. But actual inflation should decline at the projected average rate if the government were to stick to its inflation objectives firmly.

These "program" coefficients are the subject of our credibility analysis. Specifically, we denote the program coefficients as $\alpha(\mathrm{P}), \beta(\mathrm{P}), \sigma(\mathrm{P})^{2}$. Different programs may result in different values for these coefficients, but moving from a situation of high and persistent inflation to one of low and stable inflation, the sign of $\alpha(\mathrm{P})$ should always be negative during the stabilization period, although its actual magnitude could vary from program to program. In other words, a genuine commitment to taming inflation must imply a shift in $\alpha$-from $\alpha \geq 0$ to $\alpha(\mathrm{P})<0$ - during the disinflation process, that is, a regime change.

\section{The recursive application of Bayes' rule over the projection period implements}

Bayesian learning econometrically. Given agents' initial beliefs about the disinflation process - proxied by prior distributions on the coefficients in (1) - and the true model of the disinflation process - the likelihood function of (1) - Bayes' rule allows us to update agent's beliefs recursively and obtain posterior distributions on the disinflation parameters for each realization of the inflation rate over the projection period (for each $t=T, \ldots, T+K$, where $T$ is the month of program approval and $\mathrm{T}+\mathrm{K}$ is the last month of the projection period under the program). Given these distributions, we can then compute the posterior probability that, at

\footnotetext{
${ }^{5}$ Equation (1) implies that that inflation follows an AR(2) process, $\pi_{\mathrm{t}}=\alpha+(1+\beta) \pi_{\mathrm{t}-1}-\beta \pi_{\mathrm{t}-2}+\mathrm{e}_{\mathrm{t}}$. As Kapetanios, Pagan, and Scott (2004) noted, many rational expectation models of the monetary transmission mechanism imply such a univariate representation for the reduced form inflation. So our assumption is not particularly restrictive.
} 
each period $\mathrm{t}$, the estimated coefficient $\alpha(\mathrm{t})$ is equal to or smaller than that implied by the authorities' inflation objectives, $\alpha(\mathrm{P})$.

Theil's (1971) mixed estimator computes Bayes' rule at each realization of the inflation process. Theil's mixed estimator applies ordinary least square estimation to an augmented regression that incorporates prior information in the form of linear restrictions on the parameter vector. It is a Bayesian estimator in the sense in that there are priors which generate it as their posterior modes. ${ }^{6}$ Since the posterior distribution returned by the mixed estimator is approximately normal, for each $t$, we can easily compute the probability that the estimated coefficient $\alpha(\mathrm{t})$ is equal or smaller than $\alpha(\mathrm{P}){ }^{7}$

\section{By iterating this procedure, we eventually obtain a series of probabilities that the} estimated average fall in inflation is less than or equal to the projected average fall in inflation. For instance, given agents' prior on the true model parameters at time T-1, say $\alpha(T-1)$, where $T-1$ is the month before the program approval, mixed estimation of equation (1) over the sample period from T-S to T (where $\mathrm{S}$ is the fixed length of the series used in the analysis) provides a posterior distribution on $\alpha(\mathrm{T})$, which can be compared to $\alpha(\mathrm{P}){ }^{8}{ }^{8}$ The posterior distribution at time $\mathrm{T}$ can then be used as prior at $\mathrm{T}+1$, and the posterior at time $\mathrm{T}+1$ as prior at $\mathrm{T}+2$, and so on. Eventually, we obtain a series of posterior distributions on $\alpha(\mathrm{t})$ and a series of probabilities that these coefficients are close to the program ones for $\mathrm{t}=\mathrm{T}, \ldots$, $\mathrm{T}+\mathrm{K}$.

\section{Disinflation CRedibility in TURKey}

In this section we apply the methodology described above to assess how the credibility of the disinflation program in Turkey has evolved over the period after the 2001 crisis. Following the financial crisis of February 2001, the launch of a strengthened economic program in May 2001 provides the natural starting point for our empirical analysis. The credibility analysis extends through March 2004, and encompasses the IMF-supported program approved in February 2002, and both domestic (mainly political) and external shocks, such as September 11, 2001 and the Iraq war. Thus, the data span the period June 1995-December 2004 (Figure $1)$.

\footnotetext{
${ }^{6}$ See Theil (1971, pp. 670-672) and the RATS manual (section 5.8) for more details.

${ }^{7}$ Note that, by construction, credibility cannot reach one at the beginning of the sample even if actual inflation were equal to projected inflation. While this is an undesirable property of our measure, in practice the bias is very small. In fact, results are essentially the same when we compute the program coefficients recursively at each time t, i.e., letting program coefficient change at each time $t$ like the actual coefficients of the credibility analysis.

${ }^{8}$ The choice of S, which determines the constant length of the series entering the credibility analysis, may be pinned down by an assumption on the width of the agents' memory span.
} 


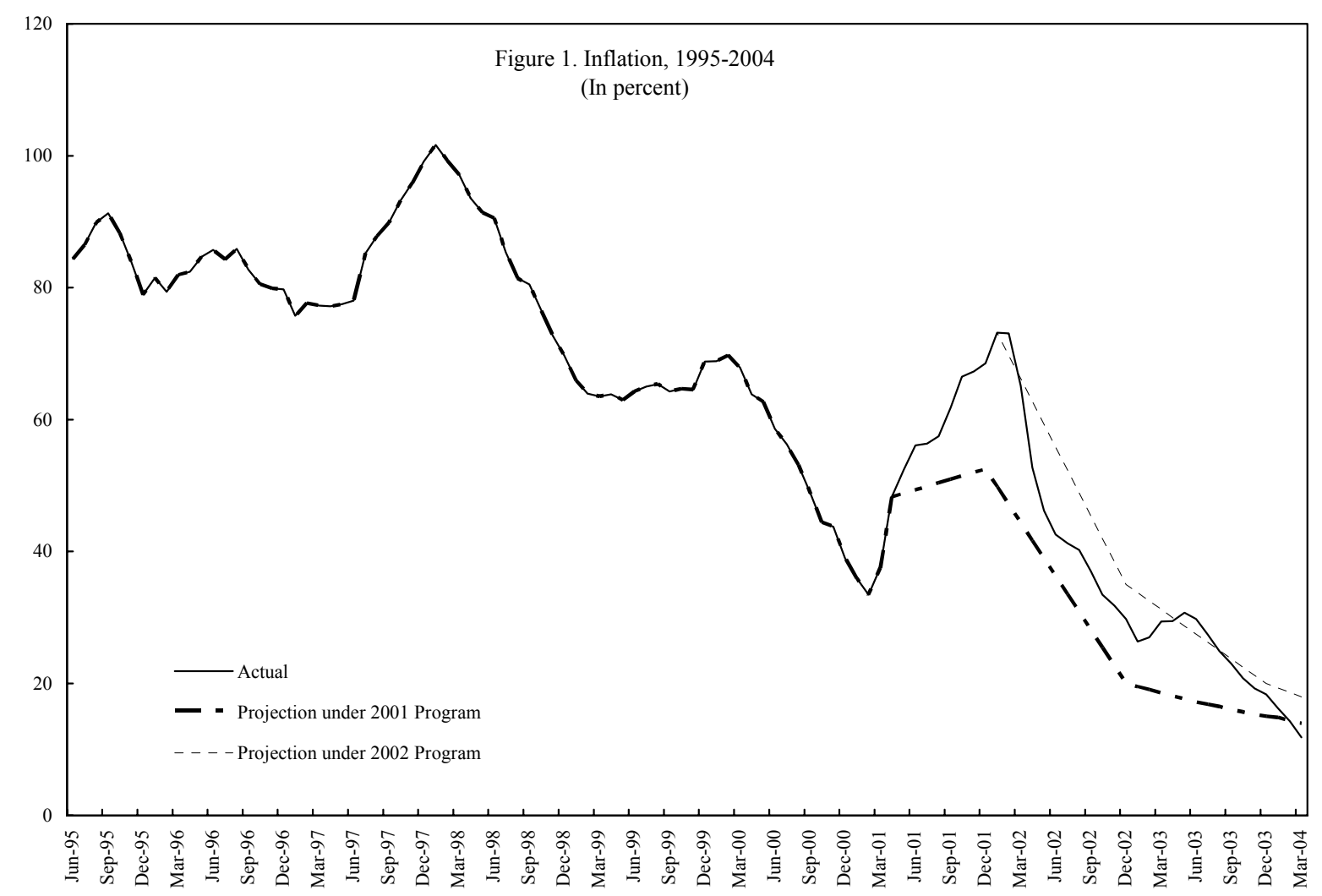

Sources: Turkish authorities; and IMF staff estimates.

There are two sets of program coefficients - since we consider two IMF-supported programs - and one set of prior coefficients (Table 1). The first set is obtained on historical data from June 1995 to April 2001 — up until an augmented IMF-supported program was approved after the 2001 crisis - and projections from May 2001 to December 2002 - that is, the end of the original three-year IMF-supported program approved in December 1999). The second set is obtained based on historical data from June 1995 to January 2002 - that is, last month before a new IMF-supported program was approved - and projections from February 2002 to December 2004 - that is, the end of the new program. For both programs, the annual inflation targets are those published in the respective letter of intent with the IMF. ${ }^{9}$ We derive monthly inflation projections by assuming a constantly decreasing monthly inflation rate - that is, by assuming a gradual disinflation path in the absence of shocks. Prior coefficients (the mean and the variance of the of the initial prior distribution on the parameters of the model) are estimated by fitting equation (1) over the period preceding the $2001 \mathrm{IMF}$-supported program announced after the financial crisis, that is, June 1995-April 2001. Consistent with a standard two-year forecasting horizon under most inflation targeting regimes, we set $\mathrm{S}$, the constant length of the series entering the credibility analysis, equal to 24 months and check the sensitivity of the results to alternative values (e.g., S equal 18, 36, and 48 months).

\footnotetext{
${ }^{9}$ These are available at www.imf.org.
} 
Table 1. Priors and Program Coefficients

\begin{tabular}{|c|c|c|c|c|c|c|}
\hline & \multicolumn{2}{|c|}{2001 Program coefficients } & \multicolumn{2}{|c|}{2002 Program coefficients } & \multicolumn{2}{|c|}{ Prior coefficients } \\
\hline & Value & t-statistic & Value & t-statistic & Value & t-statistic \\
\hline$\alpha$ & -0.38 & -1.40 & -0.28 & -1.24 & -0.16 & -0.48 \\
\hline$\beta$ & 0.39 & 4.31 & 0.46 & 6.03 & 0.39 & 3.56 \\
\hline No. of observations & 91 & & 115 & & 71 & \\
\hline R-square & 0.17 & & 0.24 & & 0.15 & \\
\hline Sample & \multicolumn{2}{|c|}{ June 1995-December 2002} & \multicolumn{2}{|c|}{ June 1995-December 2004} & \multicolumn{2}{|c|}{ June 1995-April 2001} \\
\hline
\end{tabular}

Sources: IMF staff estimates.

Estimated program coefficients imply a marked acceleration in the disinflation process with the 2001 program when compared to the prior values. The historical average decline in inflation is not only much smaller than that projected under the 2001 program, but also so uncertain as to make the estimated regression constant statistically not different from zero. This may be interpreted as characterizing agents with a belief that, in the absence of any policy measure, inflation would have persisted indefinitely at the then current level. By contrast, the perfect realization of the projected inflation path derived from the program would have implied a marked acceleration of the disinflation process (as measured by the $\alpha$ coefficient) and a decrease in the uncertainty around this central path (higher t-stat, which reflects lower standard errors) compared to the disinflation history. Interestingly, the estimated 2002 program coefficients imply a slight deceleration in the disinflation process, without altering the degree of uncertainty around the projection path.

Our Bayesian measure shows that the credibility of Turkey's stabilization program has improved markedly since the 2001 crisis, and is responsive to program implementation, political uncertainty and external shocks (Figure 2 , solid line). ${ }^{10}$ Credibility rises gradually, though not always monotonically, from about 35 percent in May 2001 to about 85 percent in March 2004. It stays on a steep downward path in the second half of 2001, arguably reflecting skepticism about the authorities' commitment to (and ability to deliver) disinflation, also in the face of an external shock (September 11). Implementation of the strengthened IMF-supported program since February 2002, as well as a slightly less ambitious target, however, are closely associated with a sizable improvement in credibility. Finally, delays in program implementation after the elections at the end of 2002 and the uncertainty related to the war in Iraq are captured well by the mild slowdown in credibility gains in early 2003.

${ }^{10}$ Our credibility measure, being the probability of an event, varies between 0 and 1. 


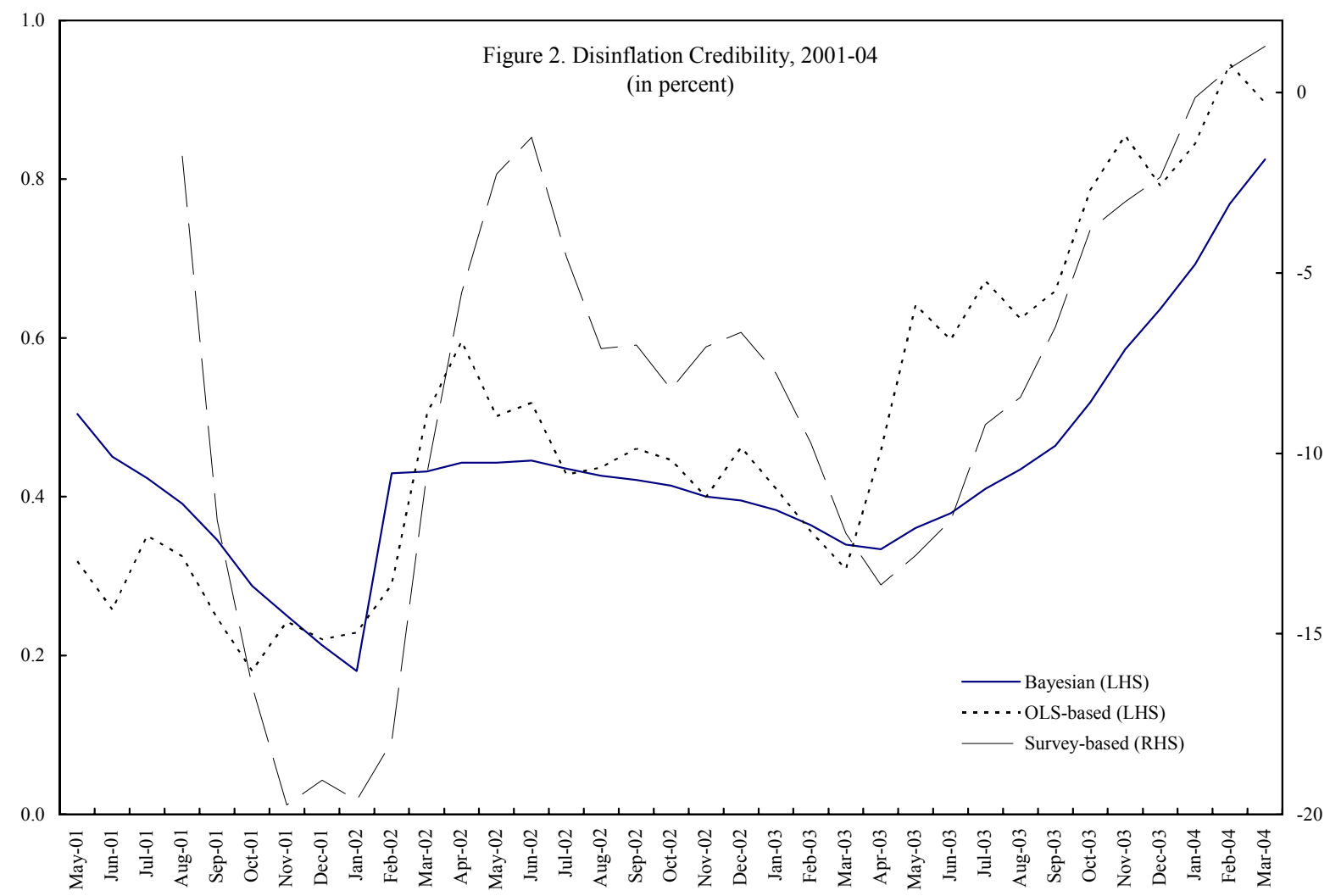

Sources: CBT inflation survey; and IMF staff estimates.

The results are robust. ${ }^{11}$ First, they are consistent with two alternative measures of credibility. The first is based on inflation expectation surveys and is computed as the difference between program inflation and expected inflation in the survey (Figure 2, longdotted line). ${ }^{12}$ The second is based on a simple, recursive OLS regression over the same periods, computed using the same program coefficients and estimation window $\mathrm{S}$ (Figure 2, dotted line). ${ }^{13}$ Both measures are, however, more volatile and sensitive to news than our

${ }^{11}$ All results not reported are available on request from the authors, together with the data and the RATS computer code used.

12 These surveys are available at www.tcmb.gov.tr. The monthly inflation projection used here are those under the two IMF-supported programs considered, which are not public.

${ }^{13}$ The main difference between the Bayesian and the OLS-based measure of credibility rests with the way agents are assumed to process information and update their priors-i.e. whether agents learn from experience or not. The Bayesian measure assumes that agents use each new inflation outturn to update their priors and revise their assessment of the disinflation program credibility over time - agents learn from experience. Each realization of the inflation process is a random draws from a new distribution, which becomes the prior for the following period. The OLS-based measure assumes that agents do not update their priors on the basis of inflation outturns. Each realization of the inflation process is a random draw from the same distribution. 
Bayesian measure. Second, the reported improvement in the credibility is robust to the use of a more pessimistic initial prior for the model's parameters (computed by including observations up to June 1991) or the use of longer estimation windows (e.g., S equal 36 or 48 moths). Both changes imply a lengthening of the agents" "memory span" to include more "high inflation" observations at the beginning of the sample or at each step of the credibility analysis. Both changes shift downward the whole estimated credibility series somewhat, but do not affect its time profile in any significant manner, including leaving the end value of the credibility series well above its initial value. Similar effects in the opposite direction result from shortening the agents' memory span assumed in the analysis. This confirms that, over the program period, there has been a marked improvement in credibility, although precise estimates of its absolute level should not be stressed.

\section{Conclusions}

Since the 2001 crisis, the Central Bank of Turkey has acted as a de facto inflation targeter. Most interest rate cuts have been presented in terms of falling inflation and inflation expectations, and confidence about reaching the end-year target. Moreover, it has publicly announced its commitment to introducing formal inflation targeting as conditions allow. Disinflation has been dramatic so far, and continued success will depend, among other things, on how credible disinflation is perceived to be.

This paper presents an empirical measure of credibility that focuses on agents' learning process. Unlike other measures, it does not rely on information about asset prices or surveys of market participants' expectations, all of which have limitations, especially in emerging markets. The main advantage of the measure developed in this paper is that (i) it uses the aggregate consumer price index, which is available and relatively reliable in most emerging market economies; (ii) it embeds information on actual price and wage setting behavior more fully than estimates of this behavior by financial markets participants; and (iii) it captures the extent to which agents' expectations are backward- or forward-looking since it reflects the expectations embedded in the consumer price index.

The empirical results indicate clearly that the credibility of the disinflation program launched by Turkey in the aftermath of the 2001 crisis has improved dramatically. This bodes well for the future of disinflation and the implementation of inflation targeting in Turkey. 


\section{APPENDIX: BAYES' RULE}

Bayesian learning is simple in principle. Assume the true model is $y=\beta x+\varepsilon$, with $\varepsilon \sim\left(0, \sigma^{2}\right)$ and that we are interested in $\beta$ and $\sigma^{2}$. Given the probability density function of the data ( $p d f)$ conditional on the model's parameters (i.e., the information contained in the data in the form of a likelihood function), $L\left(y \mid \beta, \sigma^{2}\right)$, and a joint prior distribution on the parameters, $p\left(\beta, \sigma^{2}\right)$, the joint posterior distribution of the parameters conditional on the data, $p\left(\beta, \sigma^{2} \mid Y\right)$, is obtained through Bayes' rule, $p\left(\beta, \sigma^{2} \mid Y\right)=\frac{p\left(\beta, \sigma^{2}\right) L\left(Y \mid \beta, \sigma^{2}\right)}{p(Y)}$

To see this, simply note that, by definition of conditional probability, the joint $p d f$ of the data and the parameters, $p\left(\beta, \sigma^{2}, Y\right)$, can always be written as:

$$
p\left(\beta, \sigma^{2}, Y\right)=L\left(Y \mid \beta, \sigma^{2}\right) p\left(\beta, \sigma^{2}\right)=p\left(\beta, \sigma^{2} \mid Y\right) p(Y) .
$$

Given $p\left(\beta, \sigma^{2} \mid Y\right)$, the marginal posterior distributions conditional on the data- $p\left(\sigma^{2} \mid Y\right)$ and $p(\beta \mid Y)$, which are the posterior distributions of interest - can be obtained by integrating out $\beta$ and $\sigma^{2}$ from $p\left(\beta, \sigma^{2} \mid Y\right)$, respectively. 


\section{REFERENCES}

Agénor, P R and M Taylor, 1993, "Analysing Credibility in High Inflation Countries: A New Approach,” Economic Journal, 103, 329-336.

Agénor, P.R. and M P Taylor, 1992, “Testing for Credibility Effects,” IMF Staff Papers, Vol. 39, No.3, September.

Alogoskoufis, G., 1992, “Monetary Accommodation, Exchange Rate Regimes and Inflation Persistence," Economic Journal, 102, 461-480.

Baxter, M., 1985, “The Role of Expectations in Stabilisation Policy,” Journal of Monetary Economics, Vol. 15, 343-362.

Blanchard, O-J., 1984, "The Lucas Critique and the Volcker Deflation," American Economic Review, Vol. 74, 211-215.

Celasun O., G. Gelos, and A. Prati, forthcoming, "Would 'Cold Turkey' Work in Turkey," IMF Staff Papers.

Celasun O., G. Gelos, and A. Prati, forthcoming, b, "Obstacles to Disinflation: What Is the Role of Fiscal Expectations," Economic Policy.

Christensen, M., 1987b, “On Interest-Rate Determination, Testing for Policy Credibility, and the Relevance of the Lucas Critique," European Journal of Political Economy, Vol. 3, 369-388.

Grilli, V. D. Masciandaro, and G. Tabellini, 1991, "Political and Monetary Institutions and Public Financial Policies in the Industrial Countries," Economic Policy.

Kapetanios G., A Pagan, and A. Scott, 2004, "Making a Match: Combining Theory and Evidence in Policy-Oriented Macroeconomic Modeling," (unpublished manuscript: Australian National University and University of New South Wales)

King, Mervyn, 1996, “How Should Central Banks Reduce Inflation?,” Bank of England Quarterly Bulletin, November, 434-44.

Kremers, J., 1990, “Gaining Policy Credibility for a Disinflation,” IMF Staff Papers, Vol. 37, 116-145.

Mankiw, N. J., Mirron, and D. Weil, 1987, "The Adjustment of Expectations to a Change in Regime: A Study of the Founding of the Federal Reserve," American Economic Review, Vol. 77, 358-374.

Theil, H., 1971, Principles of Econometrics, (New York: Wiley).

Weber, A., 1991, "Reputation and Credibility in the European Monetary System," Economic Policy, Vol. 12, 57-102. 